M. D. Hashem, N. K. Rashwan, The influence of resin modifiers on the performance of hot mix asphalt, pp. 867 - 885

\title{
THE INFLUENCE OF RESIN MODIFIERS ON THE PERFORMANCE OF HOT MIX ASPHALT
}

\author{
M. D. Hashem ${ }^{1, *}$, N. K. Rashwan ${ }^{2}$ \\ ${ }^{1}$ Faculty of Engineering, Minia University, Civil Engineering Department, EGYPT \\ ${ }^{2}$ Civil Eng. Dept., Industrial Education College, Beni-Suef, EGYPT, \\ Email: nmkrash@yahoo.com.
}

Received 11 December 2012, accepted 7 March 2013

\begin{abstract}
In order to study the influence of resin modifiers materials on the performance of hot mix asphalts (HMA), two types of resin modifiers were selected. One was anUnsaturated Polyester Resin (UPR) and the other was an Epoxy Resin (ER). Also, unsaturated polyester resin mixed with 3\% epoxy resin (UPRER) was used according to test results, which gave preference to $3 \%$ additions. Marshal test was conducted to study the stability, flow, bulk density, air voids (AV), voids in mineral aggregate (VMA) and voids filled with bitumen (VFA) for controlled hot asphalt mixtures and resin: modified mixtures at various resin modifiers contents. A computer program named BISAR was also used to determine the total stress, strain and displacement in $\mathrm{x}-\mathrm{y}$, and z-direction for flexible pavements constructed with these hot mix asphalts modified with resin additives.Experimental results showed that all resin-modified asphalt mixtures have higher flow, bulk density and VFA compared with control mixture. The stability of asphalt mixtures with UPPER was always higher than the control mixture. Unlike, for type ER and UPR the stability was lower than the control mixture up to $1 \%$ and $2 \%$ respectively then they increase. The UPRER gave higher stability, flow, AV and VMA than the other types. Moreover, the UPR gave the highest value of bulk density and VFA. The maximum stability occurs at 3\% resin modifiers content for all types. The total stress and strain relatively increase with the increase of mix depth till $10 \mathrm{~cm}$, then they decrease for all types of resin modifiers. The maximum total stresses and strain in case of UPRER are higher values than those achieved by ER and UPR respectively. The total displacement in case of UPRER is higher than that achieved by ER and UPR respectively. As resin modifiers can improve the field performance of asphalt mixes comprehensively, they will be of great benefit to the engineering field.
\end{abstract}

Keywords: hot asphalt mixes - modifiers- unsaturated polyester resin- epoxy resin - BISAR program.

\section{Introduction}

Modifying the asphalt mix by adding additives to the bitumen or asphalt mix has proved to help improve the performance of asphalt pavement efficiently. Among the modifiers of asphalt, fibers and polymers have gotten much attention for their expected excellent improvement effect. Various fiber and polymer modifiers, such as cellulose fiber, polyester fiber resin, epoxy resin, rock wool, fibrin and short asbestos and mineral fiber, have been widely used in different asphalt mixtures, including Stone Mastic Asphalt (SMA), Open Grade Friction Concrete (OGFC), etc[1-4].

\footnotetext{
* Corresponding author.

E-mail address:m_deep_2009@yahoo.com
} 
M. D. Hashem, N. K. Rashwan, The influence of resin modifiers on the performance of hot mix asphalt, pp. 867 - 885

The polyester resin is an unsaturated thermosetting resin produced by a reaction between several organic acids and polyhydric alcohols. It is most commonly used in the construction of molded reinforced fiber and composite products. The unsaturated polyester resin used in most molding applications is a viscous liquid requiring the addition of catalysts and accelerators to complete the curing process. Epoxy resins are polymer materials that begin as liquids and chemically change into a solid [5].The unsaturated polyester and epoxy are two types of resins which are used in this research to improve the performance of hot mix asphalts. The two types are liquid in forms.

Many former researches focused on the influence of fiber and polymer additives on the engineering properties of asphalt or asphalt mixture. Kwangetal. [6] made a study to investigate the possibility of utilizing a polyester resin for reinforcing flexible pavements. The application of a thin-layer coating with a polymer, unsaturated polyester resin (UPR) on the surface of a laboratory-prepared unmodified asphalt concrete mixture was studied as a tensile reinforcement method for such a material. Selected laboratory performance tests were conducted and the results were compared with those of a normal (uncoated) asphalt concrete mixture and a modified asphalt mixture. The polymer coating was found to be effective in improving Marshall stability, tensile strength and flexural strength of asphalt concrete.

Shopeng et al. [7] investigated the effects of polyester fibers on the rheological characteristics and fatigue properties of asphalt. The results indicated that the viscosity of asphalt binder had increased as the polyester fiber contents increased, especially at lower temperature. They confirmed that the fatigue property of asphalt mixture can be improved by adding fiber, especially at lower stress levels.

Maurer and Malasheskie [8] investigated the influence of fibers on overlay mixtures. Polyester was chosen over polypropylene because of its higher melting point. The study showed that the construction of the mixture was done without difficulty or extra equipment. The polyester fiber modified mixture was compared to several types of fiber reinforced segments and a control section, i.e. without any reinforcement. Test sections were rated for ease of construction, cost and resistance to reflection cracking.

Polypropylene fibers were used by $\mathrm{Yi}$ and Mc Daniel [10]in an attempt to reduce reflection cracking in an asphalt overlay. Although crack intensities were less on the fiber modified overlay sections, no reduction or delay in reflection cracking was observed. Sections in which the pavement had been cracked and set before the overlay were found to have less reflection cracking when fibers were used in either the base or binder layers.

WU et al. [11] conducted a dynamic modulus test and used the SuperPave simple performance tester (SPT) to study the dynamic modulus $\left(E^{*}\right)$ and phase angle $(\delta)$ for the controlling asphalt mixture and fiber-modified mixtures at various temperatures and frequencies. Their results indicated that all fiber-modified asphalt mixtures have a higher dynamic modulus compared with control mixture. Also, fatigue and rutting-resistance properties can be improved by fiber additives.Chen and Lin [12] investigated the effect of cellulose, rock wool and polyester fiber on the engineering properties of asphalt, and the test results indicated that good adhesion between fibers and bitumen enhances the load-

Journal of Engineering Sciences, Assiut University, Faculty of Engineering, Vol. 41, No. 3, May, 2013, E-mail address: jes@aun.edu.eg 
M. D. Hashem, N. K. Rashwan, The influence of resin modifiers on the performance of hot mix asphalt, pp. 867 - 885

carrying ability of asphalt-fiber mastics. Wu Shaopeng et al. [13] conducted the Dynamic Shear Rheometer (DSR) test to study the rheological properties of asphalt with various fibers. Their results indicated that the rutting-resistance property of asphalt with fibers could be improved to a large extent. Putman and Amirkhanian[14] compared the performance of Stone Matrix Asphalt (SMA) mixtures containing waste tire and carpet fibers with mixes made with commonly used cellulose and polyester fibers. The results revealed that the tire, carpet and polyester fibers significantly improved the toughness of the mixtures, but no significant difference in permanent deformation or moisture susceptibility was found.Zhuetal. [15] did madea study to determine the influence of polyester fiber on the performance of asphalt mixes.Two types of polyester fiber were selected: one is locally made and the other is imported. El-Hamarawy etal. [16] made a study to investigate the effect of adding short fibers on the mechanical properties of asphalt concrete mixes. In this research,Marshal test, indirect tensile strength and static creep test were performed on both control and fiber mixes to evaluate their performance, and the test results indicated that addition of wool, linen and fibrin fibers had exhibited an improvement of the mechanical properties of asphalt concrete mixes. El-Batal [17] studied the effect of adding two different types of polymers (HDPE, SBR) to various asphalt contents to improve the properties of asphalt mixes, especially rutting resistance. The study indicated that the addition of HDPE or SBR to asphalt cement had improved the workability of mixes by improving the mechanical properties of the aged asphalt.Naglaa [18] made a study to investigate the effect of adding PET in different concentration (11, $12,13,14$ and 15\%) of the weight of asphalt on the mechanical properties of asphalt concrete mixes. Evaluation of the performance was based on Marshall, indirect tensile strength, rutting test and bending test. These data were confirmed by the BISAR computer program.

The objective of this study was to evaluate the effect of the resin modifiers material on the properties of hot mix asphalts. These resins were: unsaturated polyester resin (UPR), epoxy resin (ER) and unsaturated polyester resin mixed with 3\% epoxy resin (UPRER). Marshal test was conducted to study these properties for controlled hot asphalt mixtures and resin - modified mixtures at various resin contents. Also, a computer program named BISAR was used to determine the total stress, strain and displacement in $\mathrm{x}-\mathrm{y}$, and $\mathrm{z}-$ direction of pavement that were flexibly constructed with these hot mix asphalts modified with resin additives.

\section{Materials used}

The crushed limestone was used as a coarse aggregate, siliceous sand as a fine aggregate and limestone dust as mineral filler. The aggregate gradation was selected according to one of the comments used gradation of the Egyptian code 1998 (Dense gradation 4C). The gradation of the combined aggregate along with the specification limit is presented in Fig.1. The nominal maximum aggregate size was $25 \mathrm{~mm}$. The bulk specific gravities of coarse aggregate, fine aggregate and mineral filler used were 2.655, 2.658 and 2.75

Journal of Engineering Sciences, Assiut University, Faculty of Engineering, Vol. 41, No. 3, May, 2013,E-mail address: jes@aun.edu.eg 
870

M. D. Hashem, N. K. Rashwan, The influence of resin modifiers on the performance of hot mix asphalt, pp. 867 - 885

respectively. The average bulk specific gravity for aggregate was 2.688.The los Angeles abrasion and absorption percent of coarse aggregate were $28 \%$ and $1.6 \%$ respectively.

The asphalt cement used was AC 60/70. This asphalt material, supplied by El-Suez is the usual asphalt grade used for asphalt pavement construction in Egypt. The properties of asphalt cement used are shown in Table 1.

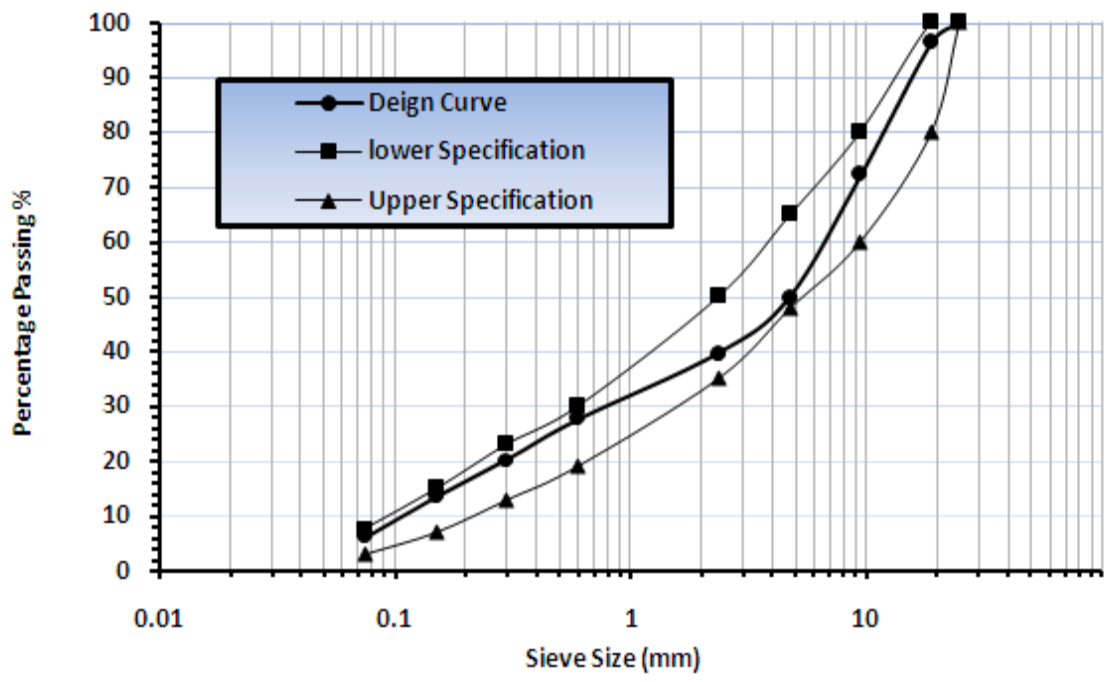

Fig.1. Grain size distribution of Aggregate used.

Table 1.

properties of asphalt cement.

\begin{tabular}{cll}
\hline \hline Tests & value & Specification \\
\hline Penetration $\left(0.1 \mathrm{~mm}\right.$ at $\left.25^{\circ} \mathrm{C}, 100 \mathrm{~g}, 5 \mathrm{~s}\right)$ & 60 & $60 / 70$ \\
Kinematic viscosity $(\mathrm{CSK})$ & 335 & +320 \\
Softening point $\left(\mathrm{c}^{\circ}\right)$ & 50 & $45 / 55$ \\
Fire point $\left(\mathrm{c}^{\circ}\right)$ & 270 & +250 \\
Ductility (at $\left.25^{\circ} \mathrm{C}\right)$ & 65 & $50-100$ \\
Specific gravity & 1.02 & $1.02-1.05$ \\
\hline
\end{tabular}

Three types of resin additives including unsaturated polyester resin (UPR), epoxy resins (ER) and unsaturated polyester resins mixed with 3\% epoxy resin (UPRER) were selected as modifiers to prepare asphalt mixtures. The properties of the unsaturated polyester resin (UPR) and epoxy resins are shown in Table 2. The contents of unsaturated polyester resin, epoxy resin and unsaturated polyester resin mixed with 3\% epoxy resin in asphalt mixtures are $1 \%, 2 \%, 3 \%, 4 \%$ and $5 \%$ of the weight of asphalt were used at O.A.C.

Journal of Engineering Sciences, Assiut University, Faculty of Engineering, Vol. 41, No. 3, May, 2013, E-mail address: jes@aun.edu.eg 
M. D. Hashem, N. K. Rashwan, The influence of resin modifiers on the performance of hot mix asphalt, pp. $867-885$

\section{Table 2.}

selected properties of UPR and ER modifier

\begin{tabular}{ccl}
\hline \hline Properties & \multicolumn{2}{c}{ Types of modifier } \\
\cline { 2 - 3 } & UPR & ER \\
S.G. $\left(25 \mathrm{C}^{\circ}\right)$ & 1.138 & 0.98 \\
Viscosity (Ps) & 3.00 & 2.25 \\
Acid Value & 20.0 & - \\
Styrene Content $(\%)$ & 40 & - \\
PH & - & 10.5 \\
Total Solid (\%) & - & 50 \\
Appearance & Clear liquid & Milky-white liquid \\
\hline \hline
\end{tabular}

\section{Experimental work}

The coarse aggregate, fine aggregate, mineral filler and asphalt cement were used to prepare the Marshal Test specimens with $65 \mathrm{~mm}$ height and $101.6 \mathrm{~mm}$ diameter. The tested asphaltic concrete mixes were composed of $60 \%$ coarse aggregate, $36 \%$ fine aggregate, $4 \%$ mineral filler and asphalt cement. For control mix, five different asphalt contents (4, 4.5, 5, 6 and 7\%) were used to prepare Marshal Test specimens. The results of Marshal Design indicated that the optimum asphalt content for control mixtures was $5.3 \%$.

Resin modifiers were added separately in different concentration to asphalt cement and mixed for one minute. After mixing hot aggregate with asphalt cement with resin modifier, samples were compacted using Marshall Hammer with 50 blows /side to represent medium traffic volume. Marshal test was conducted on both control and resin modifiers mixes to evaluate their performance.

\section{Experimental test results}

\subsection{Effect of resin modifiers on marshal stability}

Figure 2 shows the test results of stability of all types of resin modifiers. The results had clearly shown that the epoxy resin (ER) gave higher values of stability than the unsaturated polyester resin (UPR). The reason for using unsaturated polyester resin mixed with 3\% epoxy resin (UPRER) was that the high stability value occurred at $3 \%$ epoxy resin content. The hot mix asphalt samples together with UPRER gave the highest stability, followed by ER and UPR. It reveals that the stability increases with the increase of UPRER up to 3\%, and then they decrease. Unlike, the stability decreases with the increase of both types UPR and ER content up to $1 \%$, then they increase up to $3 \%$ and then they decrease again. It was noticed that stability of asphalt mixtures with type UPPER resin modifiers was always higher than the control mixture. Unlike, for type ER and UPR the stability was lower than the control mixture up to $1 \%$ and $2 \%$ respectively, then they increase. Generally, the uses of UPR, ER and UPRER improved the marshal stability, especially the later mix. The 
872

M. D. Hashem, N. K. Rashwan, The influence of resin modifiers on the performance of hot mix asphalt, pp. 867 - 885

reason may be, in this asphalt mixed with resin modifiers having a suitable consistency to cover all aggregate particles resulting in a strong bond between aggregate particles and leads to increase stability values.

Figure 3 shows the percentage of increase in stability due to adding resin modifier to hot mix asphalts at 3\% resin content compared with control mix. Marshal stability increased by $4.76 \%, 9.63 \%$ and $16.17 \%$ for mixtures containing UPR,ER and UPRER respectively.

\subsection{Effect of resin modifiers on marshal flow}

Figure 4 shows the test results of flow for all modified types. It reveals that the flow increases with the increase of resin modifiers content up to $2 \%$ with all types of resins, then it decreases. It is clear from the results that the unsaturated polyester resin mixed with $3 \%$ epoxy resin (UPRER) gave the highest values of flow, than the unsaturated polyester resin (UPR) and epoxy resin (ER) respectively.

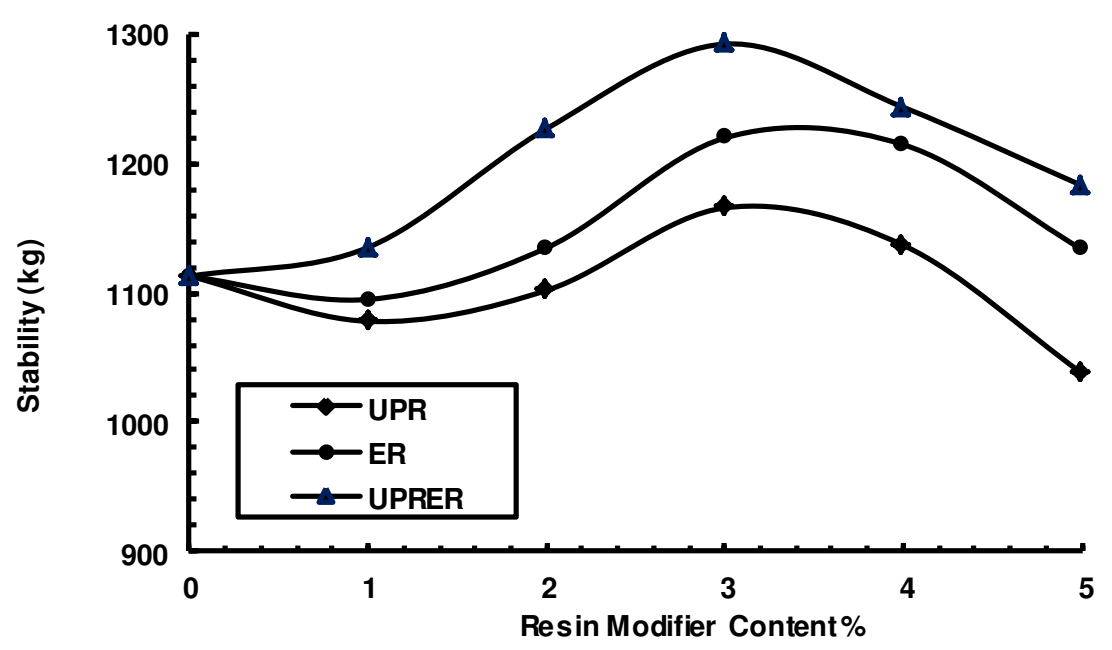

Fig. 2. Marshal Stability Versus Resin Modifiers Content

\subsection{Effect of resin modifiers on bulk density}

The relationships between resin modifiers content and bulk density are illustrated in Fig.5. It was noticed that the bulk density values increased by increasing resin modifiers content for all types of resins modifiers up to $2 \%$, then they decreased. It was also noted that the highest bulk density for mixtures containing resins was obtained for mixes with the unsaturated polyester resin (UPR). The types with epoxy resin (ER) and unsaturated

Journal of Engineering Sciences, Assiut University, Faculty of Engineering, Vol. 41, No. 3, May, 2013,E-mail address: jes@aun.edu.eg 
M. D. Hashem, N. K. Rashwan, The influence of resin modifiers on the performance of hot mix asphalt, pp. 867 - 885

polyester resin mixed with 3\% epoxy resin (UPRER) gave the lowest values of bulk density respectively.

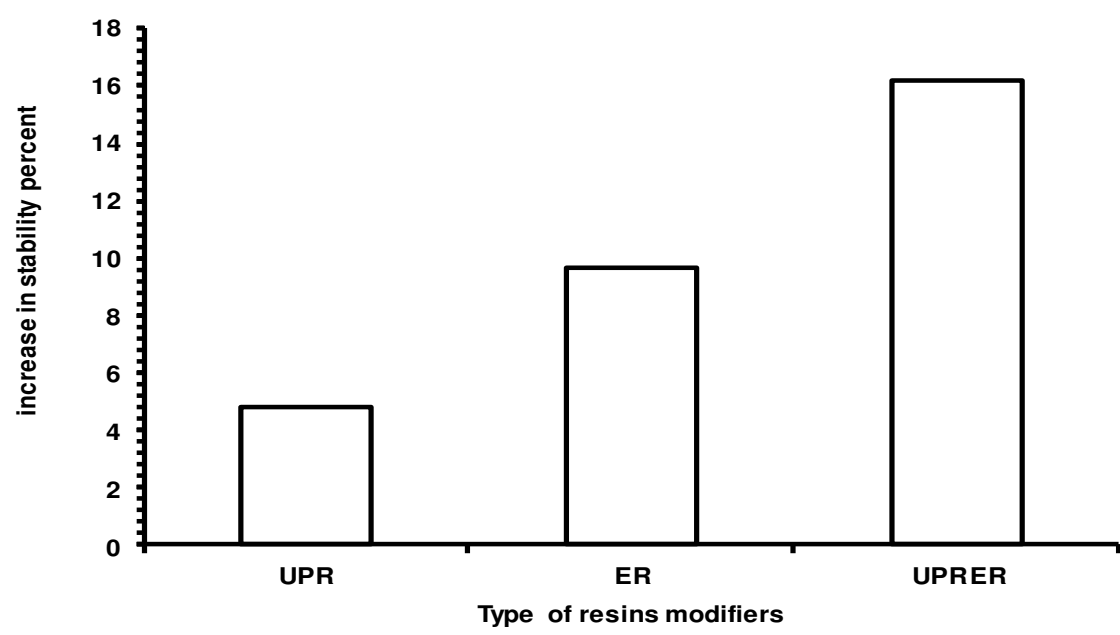

Fig. 3. Percent Increase In Marshal Stability at 3\% Resin Content Compared With Control Mix.

\subsection{Effect of resin modifiers on air voids}

Figure 6 shows air voids versus resins modifiers content for all types of resins. It reveals that the air voids decrease with the increase of resins content for all types of resin modifiers up to $2 \%$, then they increase. This result may come up because the resin modifiers fill some of the voids of asphalt concrete samples. The hot mix asphalt samples together with the unsaturated polyester resin mixed with 3\% epoxy resin (UPRER) gave the highest values of air voids, than the epoxy resin (ER) and unsaturated polyester resin (UPR) respectively.

\subsection{Effect of resin modifiers on VMA}

The relationships between resins modifiers content and Voids in Mineral Aggregate (VMA) are illustrated in Figure 7. It reveals that the (VMA) values decrease with the increase of resin modifiers content for all types of resins up to $2 \%$, then they increase. This result may be shown because the resin modifiers fill some of the voids of mineral aggregate in asphalt concrete samples. The mixtures samples together with UPRER gave the highest values of VMA, than the ER and UPR respectively.

Journal of Engineering Sciences, Assiut University, Faculty of Engineering, Vol. 41, No. 3, May, 2013,E-mail address: jes@aun.edu.eg 
M. D. Hashem, N. K. Rashwan, The influence of resin modifiers on the performance of hot mix asphalt, pp. 867 - 885

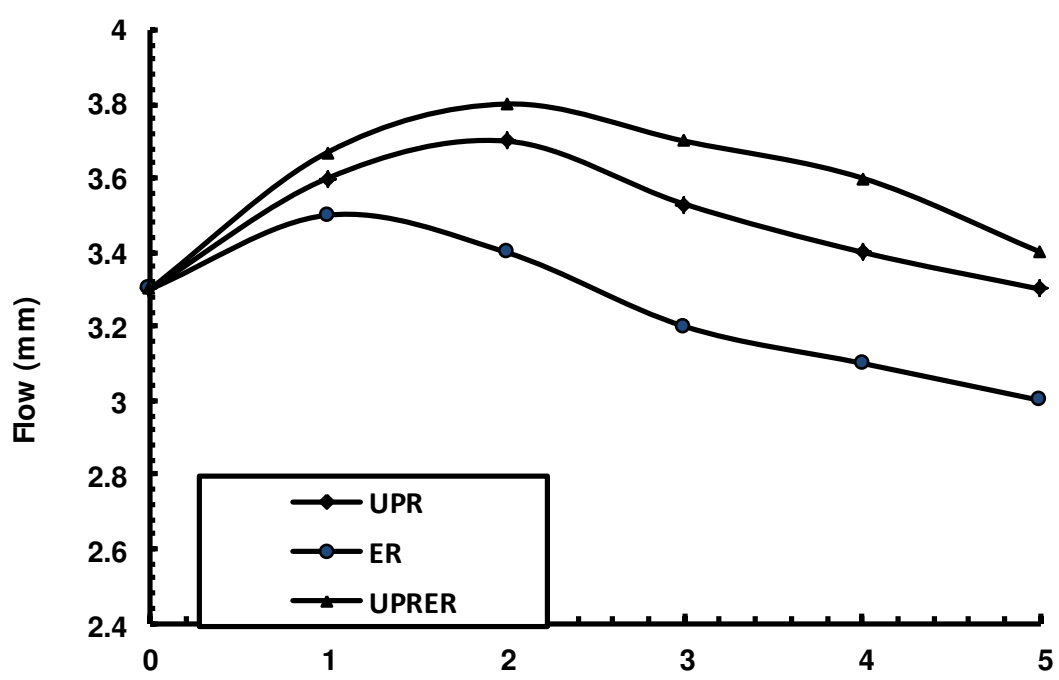

Resin Modifiers Content \%

Fig. 4. Marshal Flow Versus Resin Modifiers Content.

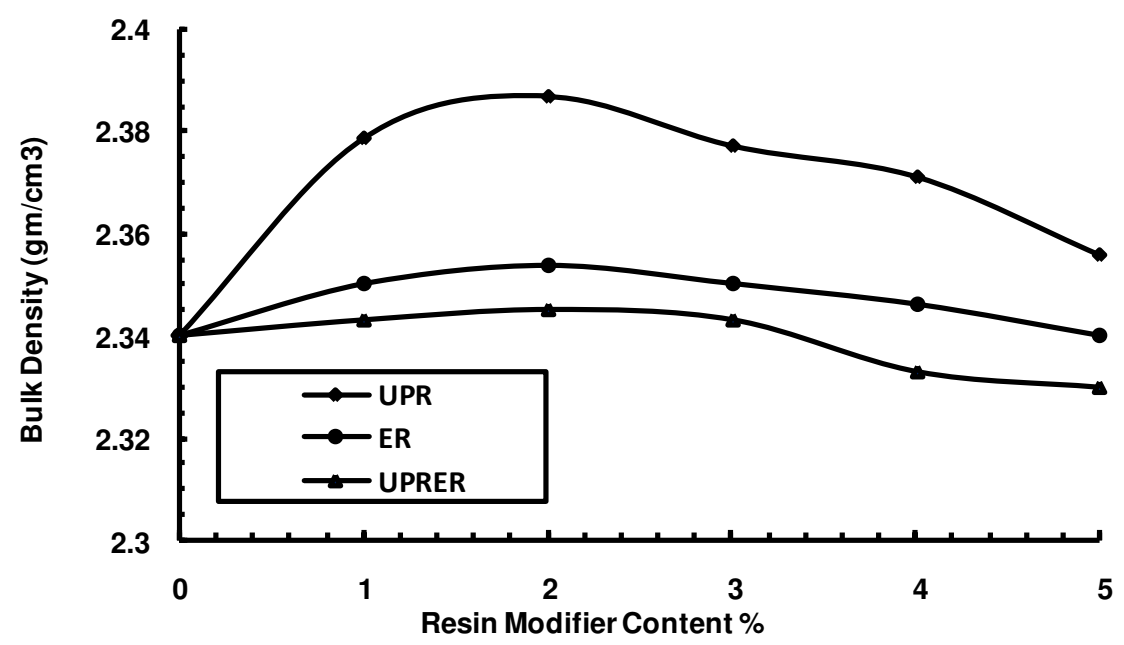

Fig. 5. Bulk Density Versus Resin Modifiers Content.

Journal of Engineering Sciences, Assiut University, Faculty of Engineering, Vol. 41, No. 3, May, 2013, E-mail address: jes@aun.edu.eg 
M. D. Hashem, N. K. Rashwan, The influence of resin modifiers on the performance of hot mix asphalt, pp. 867 - 885

\subsection{Effect of resin modifiers on VFA content}

Figure 8 shows voids filled with bitumen (VFA) versus resin modifiers content for all types of resins. It reveals that the (VFA) increase with the increase of resin modifiers content for all types of resins up to $2 \%$, and then they decrease. The mixtures samples together with UPR gave the highest values of VFA, than the ER and UPRER respectively.

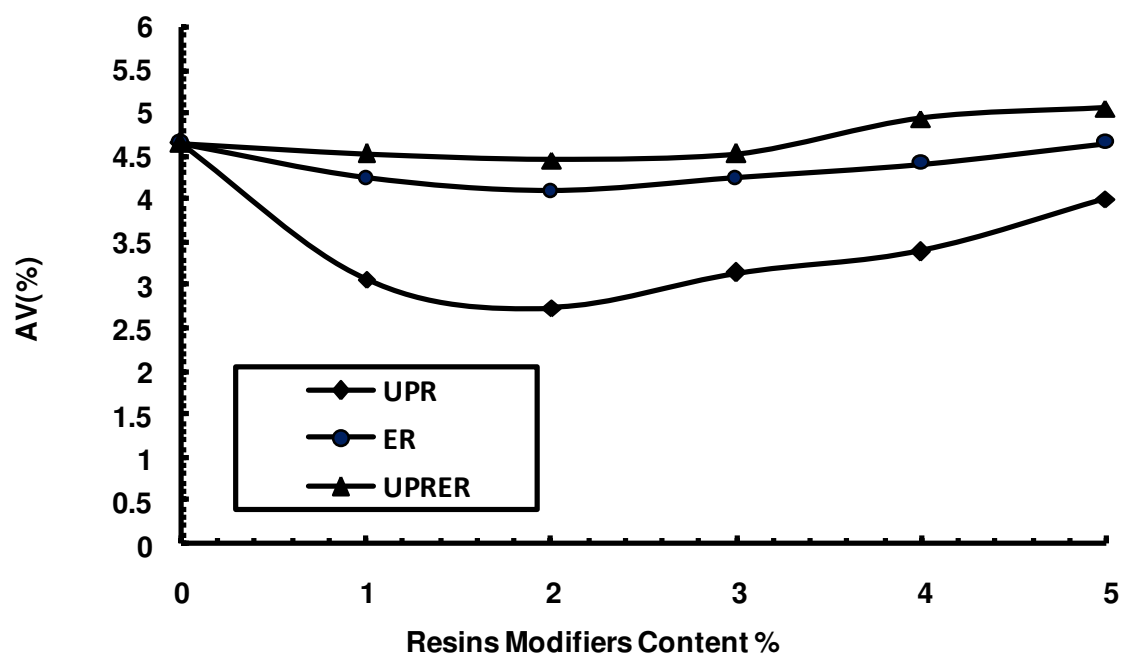

Fig. 6.Air Voids Versus Resin Modifiers Content.

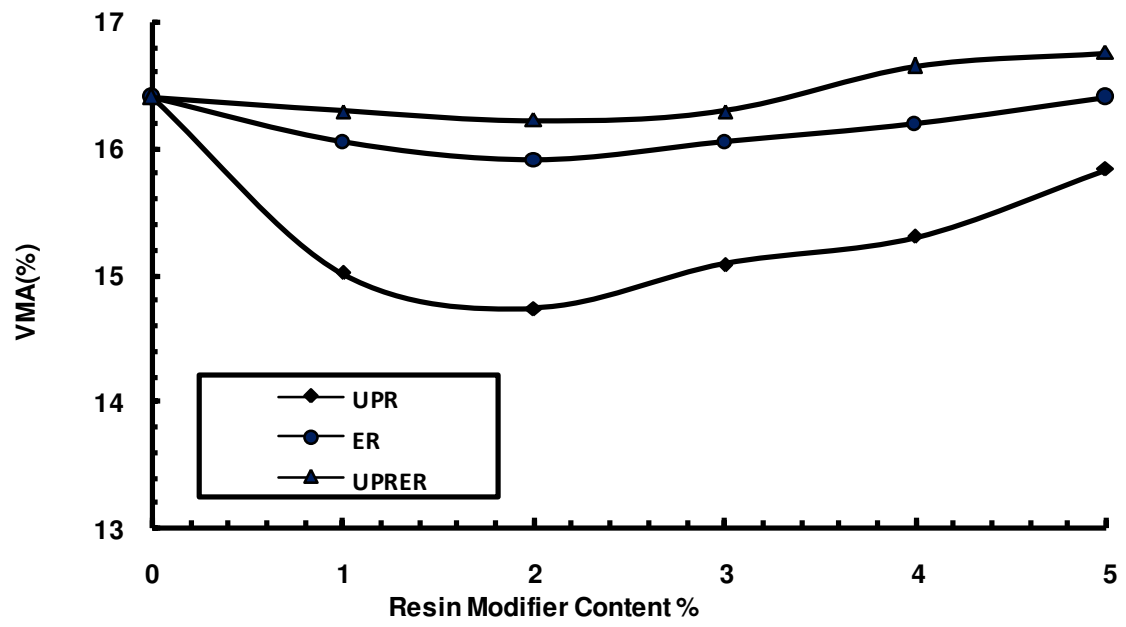

Fig. 7. VMA Content Versus Resin Modifiers Content.

Journal of Engineering Sciences, Assiut University, Faculty of Engineering, Vol. 41, No. 3, May, 2013, E-mail address: jes@aun.edu.eg 
M. D. Hashem, N. K. Rashwan, The influence of resin modifiers on the performance of hot mix asphalt, pp. 867 - 885

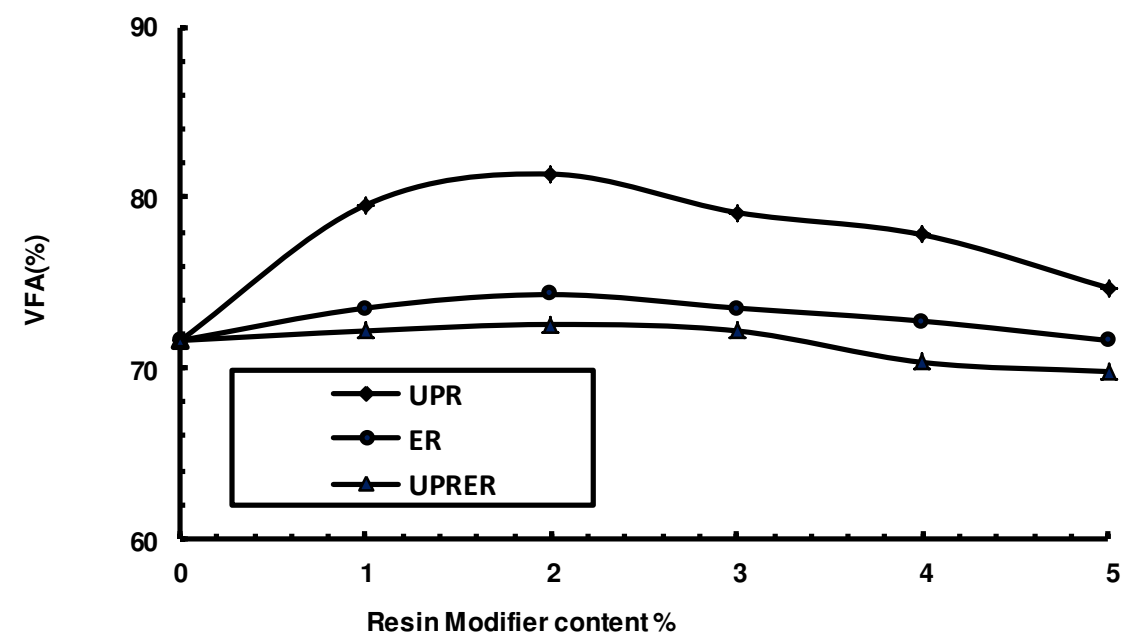

Fig. 8.VFA Content Versus Resin Modifiers Content.

\section{Numerical analysis of flexible pavement modified with resins using bisar}

\subsection{General}

Using both experimental work results of hot mix asphalt samples at $3 \%$ percent of additive resins for different types of resins and a computer program named BISAR, the total stress, strain and displacement in $\mathrm{x}-\mathrm{y}$, and $\mathrm{z}$-direction of flexible pavement constructed with hot mix asphalt mixed with resin additives were calculated.

The response model, BISAR 3.0, is a Windows version of linear elastic multi-layer program. BISAR is able to calculate stresses, strains and displacements at all points of a multi-layer pavement structure.

However, like most multi-layer models, BISAR also use several simplifications which are summarized as follows:

1. The pavement structure exists of at maximum 10 layers whereby the last layer describes the sub-grade as a semi - infinite half space.

2. All 1ayers have infinite width and length.

3. Materials of the different layers are considered to be homogeneous, isotropic and elastic. Stress and strain distribution is linear according to the theory of elasticity (Hooke)

4. Self weight of the layers is discounted

5. Load is distributed over a circular area with constant contact pressure.

For the procedure of design and analysis of pavement structures using BISAR, the following input data are required: 
M. D. Hashem, N. K. Rashwan, The influence of resin modifiers on the performance of hot mix asphalt, pp. 867 - 885

1. Number of layers.

2. Thickness of the layers.

3. Modulus of elasticity (E) and the Poisson's ratio ( $v)$ of the layers.

4. An interface shear spring compliance at each interface to study the effect of full or partial slip among the layers.

5. Number of loads with the co-ordinates of the position of the center of the loads.

6. A combination of two of the following three components to indicate the load: stress, load and radius [19].

The modulus of resilience $\mathbf{M}_{\mathrm{r}}$ for different use mixes was determined using stability obtained from experimental results of asphalt concrete mix samples according to the Egyptian Code part 5. Using AASHTO method, the thickness of various types of layers of flexible pavement was determined using parameters shown in Table (3).

\section{Table 3.}

different parameters used in AASHTO design

\begin{tabular}{ccccccccc}
\hline \hline Type & Stability (Ib) & $\mathbf{M}_{\mathbf{r}}$ (psi) & $\mathbf{a}_{\mathbf{1}}$ & $\mathbf{a}_{\mathbf{2}}$ & $\mathbf{a}_{\mathbf{3}}$ & $\mathbf{S N}_{\mathbf{1}}$ & $\mathbf{S N}_{\mathbf{2}}$ & $\mathbf{S N}_{\mathbf{3}}$ \\
\hline UPR & 2500 & $520 \times 10^{3}$ & 0.495 & 0.14 & 0.11 & 2.4 & 2.64 & 4.46 \\
ER & 2700 & $570 \times 10^{3}$ & 0.525 & 0.14 & 0.11 & 2.4 & 2.64 & 4.46 \\
UPRER & 2925 & $625 \times 10^{3}$ & 0.555 & 0.14 & 0.11 & 2.4 & 2.64 & 4.46 \\
\hline \hline
\end{tabular}

For analyzing the pavement structure, we have chosen the layers thicknesses in the pavement model because they are close to those of the existing pavement. The pavement structure selected for this study obtained from AASHTO design method consists of 100, $120,140 \mathrm{~mm}$ thickness of asphalt surface layer modified with UPR, ER and UPRER respectively, a $300 \mathrm{~mm}$ thickness granular crushed limestone layer as a base course, a 150 $\mathrm{mm}$ thickness granular crushed limestone layer as a subbase and a subgrade (silty soil) at the bottom. The configuration for structure used in the analysis is illustrated in Figure 9. The material characteristics used in the analysis are considered to be representative of the variety in the selected pavement structures. They are summarized in Table (4).

The data shown in Table (4) are fed to the BISAR computer program to obtain the total stress, strain and displacement due to loading on the surface of pavement.

\subsection{Pavement analysis results and discussion}

The contact forces distribution inside the pavement and its behavior has been monitored. Figure 10 shows how the contact forces induced by loading process are distributed inside the pavement.They develop at the contact patches, spread in the asphalt layers and then in the sub-base course. They have a radial distribution around each contact patch and their intensity is mostly compressive.

Journal of Engineering Sciences, Assiut University, Faculty of Engineering, Vol. 41, No. 3, May, 2013,E-mail address: jes@aun.edu.eg 
878

M. D. Hashem, N. K. Rashwan, The influence of resin modifiers on the performance of hot mix asphalt, pp. 867 - 885

\section{Table 4.}

Layer thickness and elastic material properties used in the analysis

\begin{tabular}{cccccc}
\hline \hline $\begin{array}{c}\text { Layer } \\
\text { No. }\end{array}$ & Material & $\begin{array}{c}\text { Resin } \\
\text { type }\end{array}$ & $\begin{array}{c}\text { Thickness } \\
(\mathrm{mm})\end{array}$ & $\begin{array}{c}\text { Modulus of Elasticity } \\
(\mathrm{E}) \mathrm{kg} / \mathrm{cm}^{2}\end{array}$ & $\begin{array}{c}\text { Poisson's } \\
\text { ratio }(\mathrm{v})\end{array}$ \\
\hline 1 & Surface & UPRER & 100 & 3600 & 0.35 \\
& layer & ER & 120 & 3500 & 0.35 \\
& & UPR & 140 & 3400 & 0.35 \\
2 & Base & & 300 & 500 & 0.37 \\
3 & Subbase & & 150 & 150 & 0.45 \\
4 & Subgrade & & infinite & 50 & 0.49 \\
\hline \hline
\end{tabular}

The effect of pavement depth on deflection, stress and strain was determined. The responses obtained at planes of symmetry and through C.L. of wheel at surface and layers interface and subgrade are analyzed and described in the following section. Figure 11 below shows the locations at which deflection, stress and strain were determined, analyzed and described.

\subsubsection{Effect of resin modifiers on total stress}

Figures 12 and 13 show the total stress versus the depth under the pavement surface for pavement modified with all types of resins at $3 \%$ content in the direction of $\mathrm{xx}$, yy and $\mathrm{zz}$. It is noticed that the total stress increases as the depth increases to $10 \mathrm{~cm}$, then by increasing depth than $10 \mathrm{~cm}$ it decrease still it reaches approximately a zero value. The maximum total stresses in case of UPRER have the highest values, then those achieved by ER and UPR respectively. That is the modulus of resilience of UPRER is higher than that of ER and UPR respectively.

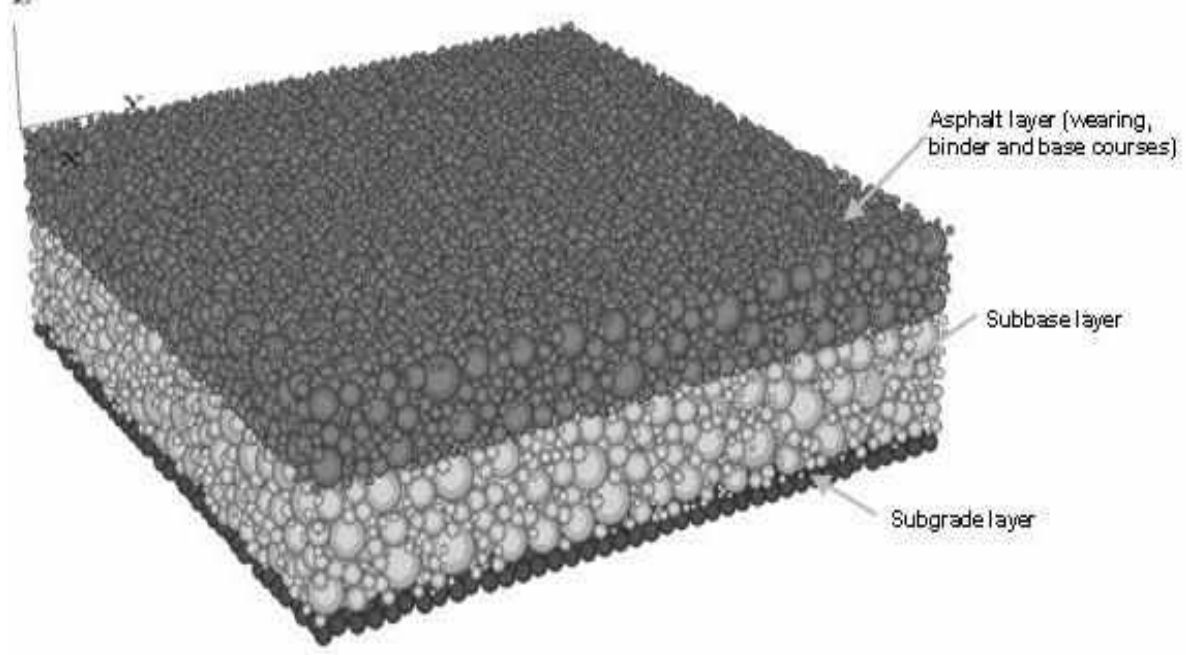

Fig.9.Pavement configuration used in analysis.

Journal of Engineering Sciences, Assiut University, Faculty of Engineering, Vol. 41, No. 3, May, 2013, E-mail address: jes@aun.edu.eg 
M. D. Hashem, N. K. Rashwan, The influence of resin modifiers on the performance of hot mix asphalt, pp. 867 - 885
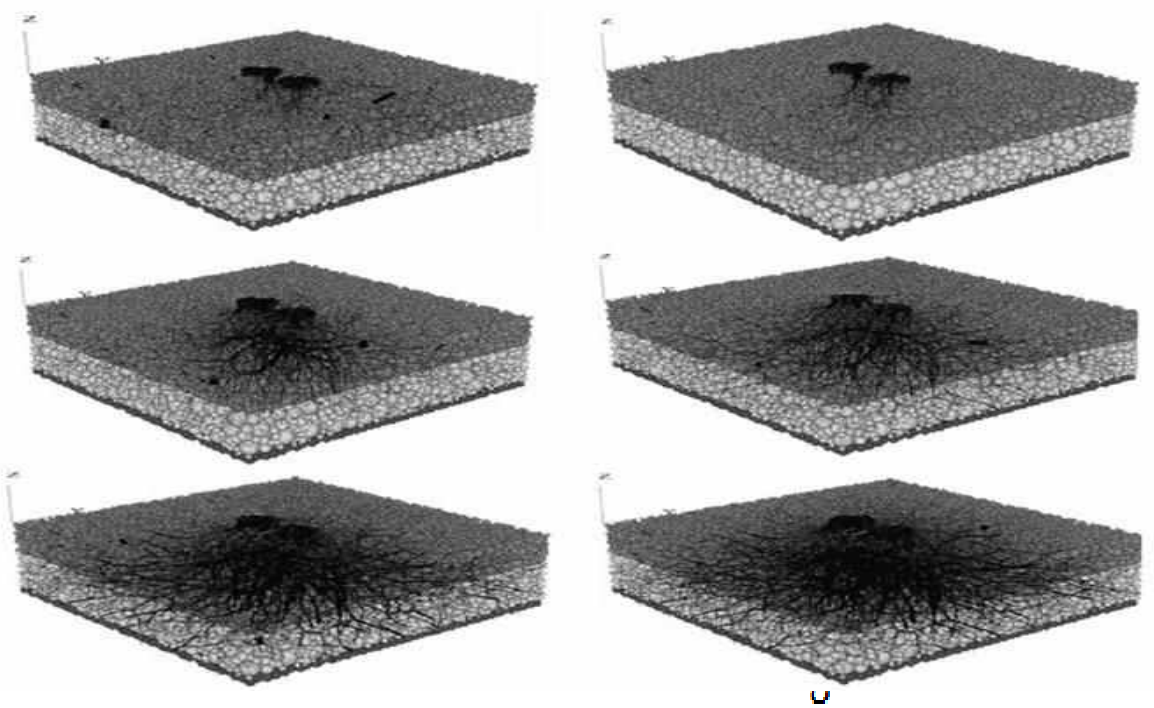

Fig. 10. Contact forces distribution inside the specimen during the loading.

\section{Locations}

\section{On Surface}

On Base Surface

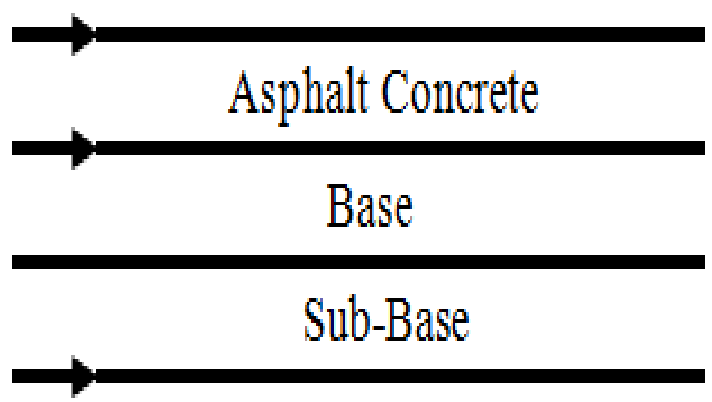

Subgrade

Fig. 11. Pavement surface location at which deflection, stress and strain were determined

Journal of Engineering Sciences, Assiut University, Faculty of Engineering, Vol. 41, No. 3, May, 2013, E-mail address: jes@aun.edu.eg 
M. D. Hashem, N. K. Rashwan, The influence of resin modifiers on the performance of hot mix asphalt, pp. 867 - 885

\subsubsection{Effect of resins modifiers on total strain}

The relationship between total strain of different resins and the depth under pavement surface in the direction of xx, yy are shown in Figures 14. It is noticed from this figure that the total strain increases with the increase of depth till $10 \mathrm{~cm}$, then by increasing depth than $10 \mathrm{~cm}$ it decreases. The maximum total strain in case of UPRER has the highest values, then the ones achieved by ER and UPR respectively.

Figure 15 shows the relationship between the total strain and the depth under pavement surface in the direction of $\mathrm{zz}$ for all types of resins modifier. It is noticed from this figure that the total strain for UPRER increases with the increase of depth till $10 \mathrm{~cm}$, then it decreases. Unlike, for types ER and UPR the total strain decreases with the increase of depth till $10 \mathrm{~cm}$, then by increasing depth than $10 \mathrm{~cm}$ it increases.

\subsubsection{Effect of resin modifiers on total displacement}

Figure 16 shows the total displacement versus the depth under the pavement surface for pavements modified with all types of resins in the direction of zz. It is noticed that the total displacement decreases with the increase of depth. The total displacement in case of UPRER has higher values than that achieved by ER and UPR respectively.

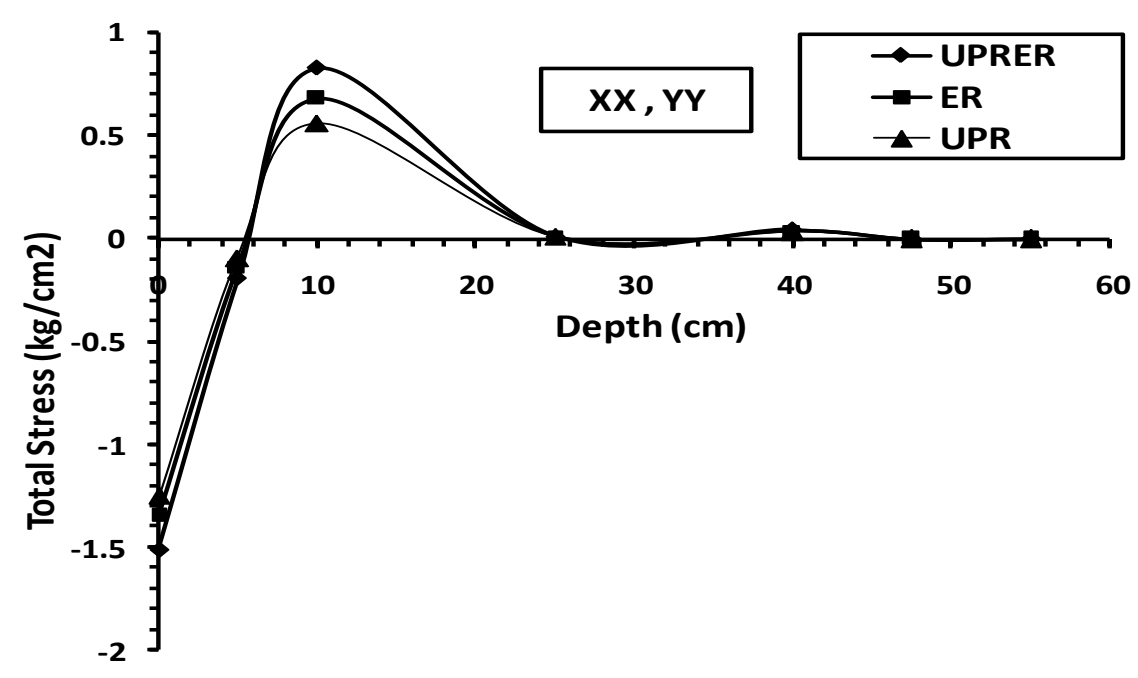

Fig. 12.Total stress versus depth under pavement surface at direction $\mathrm{xx}$ and yy for all types of resins modifiers.

Journal of Engineering Sciences, Assiut University, Faculty of Engineering, Vol. 41, No. 3, May, 2013, E-mail address: jes@aun.edu.eg 
M. D. Hashem, N. K. Rashwan, The influence of resin modifiers on the performance of hot mix asphalt, pp. $867-885$

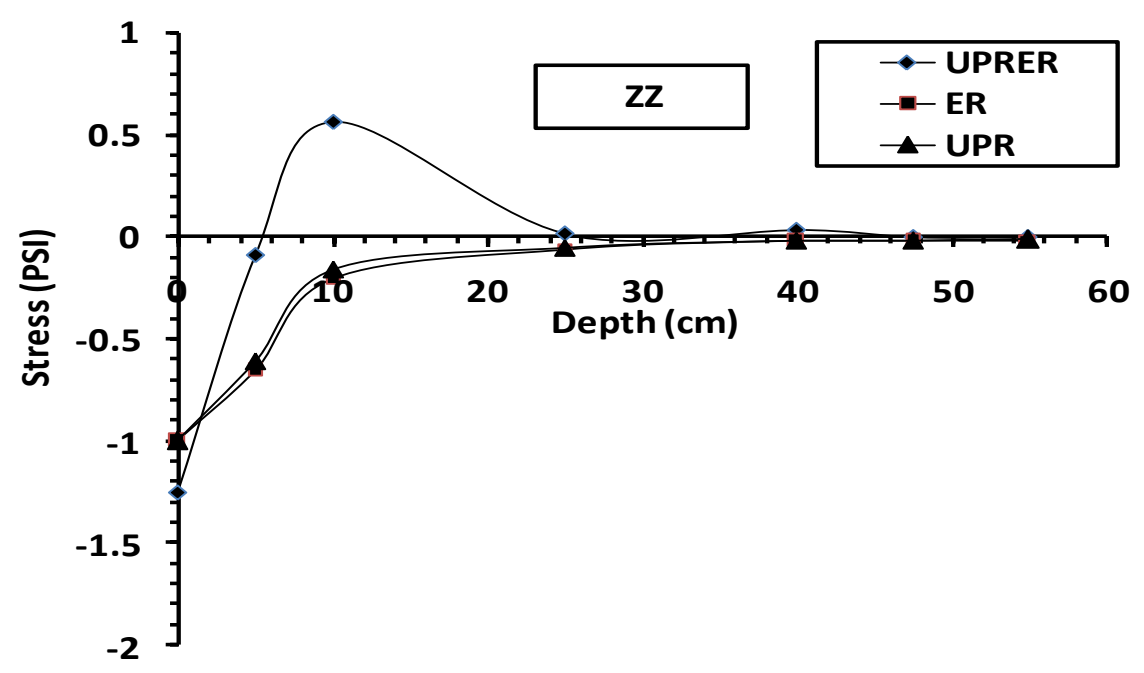

Fig. 13.Total stress versus depth under pavement surface at direction $\mathrm{zz}$ for all types of resin modifiers.

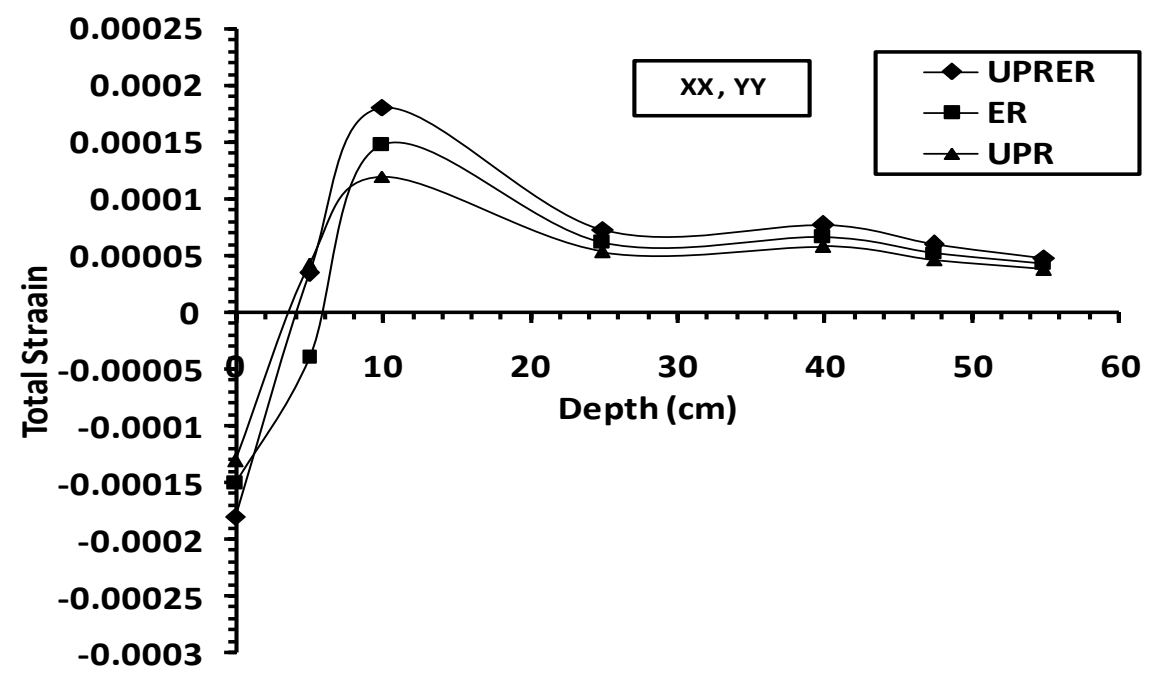

Fig. 14.Total strain versus depth under pavement surface at direction $x x$ and yy for all types of resins modifier.

Journal of Engineering Sciences, Assiut University, Faculty of Engineering, Vol. 41, No. 3, May, 2013, E-mail address: jes@aun.edu.eg 
M. D. Hashem, N. K. Rashwan, The influence of resin modifiers on the performance of hot mix asphalt, pp. 867 - 885

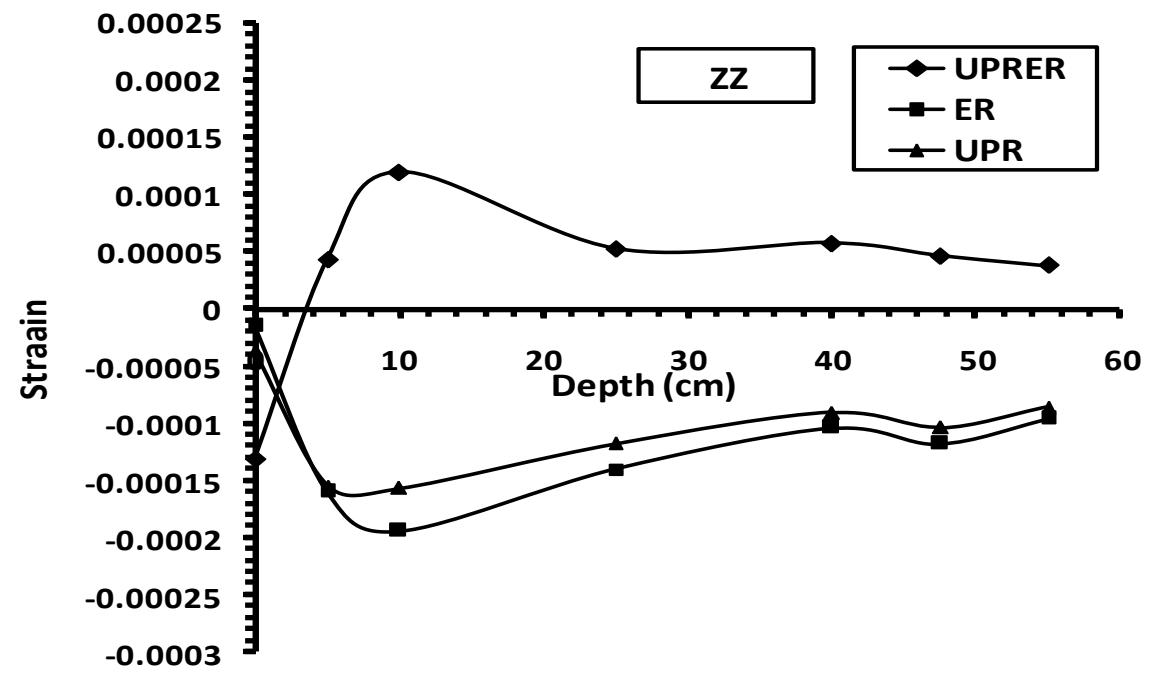

Fig. 15.Total strain versus depth under pavement surface at direction $\mathrm{zz}$ for all types of resin modifiers.

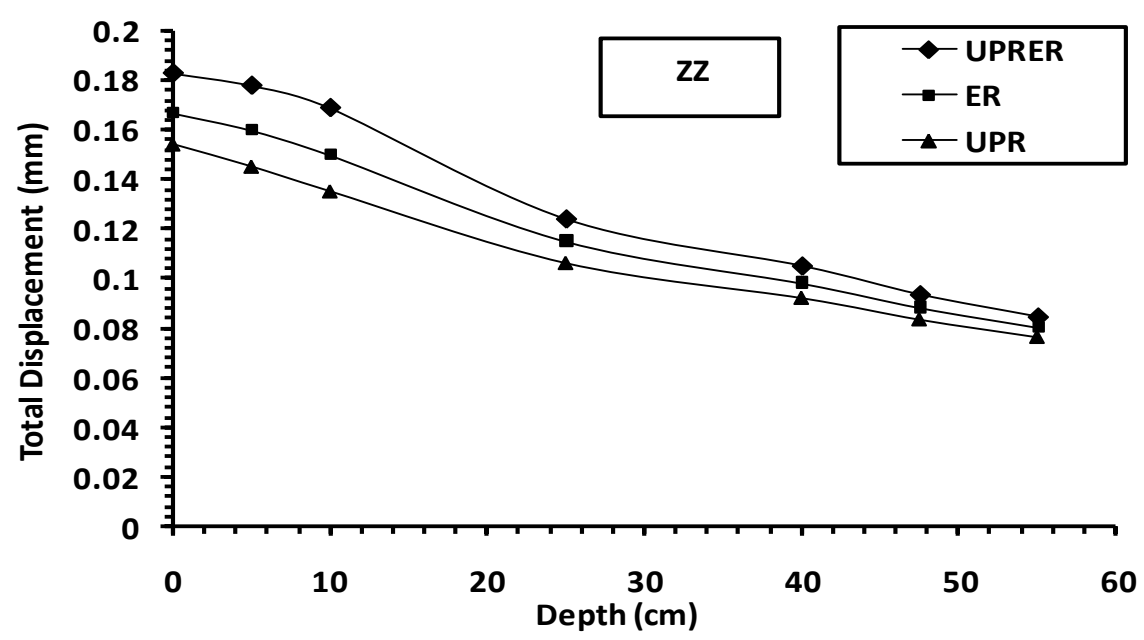

Fig. 16.Total displacement versus depth under pavement surface at direction for all types of resins.

Journal of Engineering Sciences, Assiut University, Faculty of Engineering, Vol. 41, No. 3, May, 2013, E-mail address: jes@aun.edu.eg 
M. D. Hashem, N. K. Rashwan, The influence of resin modifiers on the performance of hot mix asphalt, pp. 867 - 885

\section{Conclusions}

Based upon the analysis of the experimental investigation and numerical analysis of flexible pavement using BISAR program presented in this study, the following conclusions are drawn:

1. Marshal stability for mixes with resin additives (polyester, epoxy and polyester mixed with 3\% epoxy)has improved compared with the conventional mixtures.

2. Maximum Stability values were achieved at $3 \%$ resin content of the weight of asphalt cement for all types of resins.

3. At $3 \%$ resin content, Marshal stability increased by $4.76 \%, 9.63 \%$ and $16.17 \%$ for mixtures containing UPR, ER and UPRER respectively.

4. Marshal Stability of mixtures using UPRER was higher than UPR and ER.

5. Bulk density values increased by increasing resin content up to $2 \%$ for all types of resins, then they decrease. Also, UPR gave the highest values of bulk density followed by ER and by UPRER.

6. The addition of about $2 \%$ resins to the weight of asphalt cement for all different resins gave a higher value of flow when compared with the other percentages of resins. Also, the flow values of asphalt concrete mixtures with ER were lower than those of mixtures containing UPR and UPRER respectively.

7. Both the Air voids (AV) and the Voids in Mineral Aggregate (VMA) decreased by increasing resin content up to $2 \%$ for all types of resins, then they increased. The UPR gave the lowest values.

8. The voids filled with bitumen (VFA) percent increased with the increase of resin additive content for all types of resins up to $2 \%$, then they decreased.

9. Both the total stress and strain increase with the increase of depth till $10 \mathrm{~cm}$, then by increasing depth than $10 \mathrm{~cm}$ it decreased for all types of resin modifiers. The maximum total stresses and strain in case of UPRER have higher values than those achieved by ER and UPR respectively.

10. The total displacement decreased with the increase of depth. In the case of UPRER the total displacement has higher values than that achieved by ER and UPR respectively.

\section{References}

[1]Reed B.F, James L, Burati J.R. Polyester Fibers in AsphaltPaving Mixtures [J]. Journal of the Association of AsphaltPaving Technologists, 1996, 65(1): 65-66

[2] Serfass J.P, Samanous J. Fiber-Modified Asphalt ConcreteCharacteristics, Application and Behavior [J]. Journal ofthe Association of Asphalt Paving Technologists, 1996, 65:193-230

[3] Harris B.M, Stuart K.D. Analysis of Mineral Fillers and MasticsUsed in Stone Matrix Asphalt [J]. Journal of the Association of Asphalt Paving Technologists, 1995, 64(1): 211 234

[4] Bueno, B.S, Silva W.R, Lima D.C, et al. Engineering Properties of Fiber Reinforced Cold Asphalt Mixes[J]. Journal ofEnvironmental Engineering, 2003, 10: 952-955.

Journal of Engineering Sciences, Assiut University, Faculty of Engineering, Vol. 41, No. 3, May, 2013, E-mail address: jes@aun.edu.eg 
M. D. Hashem, N. K. Rashwan, The influence of resin modifiers on the performance of hot mix asphalt, pp. 867 - 885

[5] Paul Scott, Edited By: R. Halprin, Copyright Protected:"Polyester and Epoxy" 2003-2012. Conjecture Corporation.

[6]Kwang W. Kim, Yong-Churl Park and Kyu-SeokYeon, Tensile reinforcement polymer coating.Construction and Building Materials.Vol. 10.No. 2.1996. pp. 141-146.

[7] Shaopeng W, Qunshan Y, Ning L. Investigation of rheological and fatigue properties of asphalt mixtures containing polyester fibers. Construction and Building Materials.2008; 22(10):2111-5.

[9] Maurer D.A, Malasheskie G.J. Field Performance of Fabrics and Fibers to Retard Reflective Cracking.GeotextGeomem.1989; 8:239-67.

[10]Yi J, McDaniel S. Application of cracking and seating and use of fibers to control reflection cracking. Trans Res Rec. 1993;1388:150-9.

[11] WU S., YE Q., LI N., YUE H. Effects of Fibers on the DynamicProperties of Asphalt Mixtures. Journal of Wuhan University of Technoogy-MaterSci Ed. Apr, 2007. 22:733-6.

[12]Chen Jianshiuh, Lin Kueiyi. Mechanism and Behavior of Bitumen Strength Reinforcement Using Fibers [J]. Journal of Materials Science, 2005, 40: 87-95

[13] Wu Shaopeng, Chen Zhen, Ye Qunshan. Effects of Fiber Additive on the High Temperature Property of Asphalt Binder[J]. Journal of Wuhan University of Technology -Mater.Sci. Ed., 2006, 21(1): 28-31

[14] Putman B.J, Amirkhanian S.N .Utilization of Waste Fibers inStone Matrix Asphalt Mixtures[J]. Resources, Conservationand Recycling, 2004, 42: 265-274.

[15] Zhu Haoran , Yang Jun, Cong Ling, Cui Juan and Wan Jun.Influence of Polyester Fiber onthe Performance of Asphalt Mixes.Southeast University.No. 2 Sipailou, Nanjing 2000, 96, P. R. China.

[16] El-Hamrawy S., El-Baz, M. and Abdel-Baset, A.Fibers for Improving the Mechanical Properties of Asphalt Concrete Mixes.1st International Conference Of Civil Eng.Science. ICCES1.Vol.2. 2003.

[17] El-Batal, S. Improving Asphalt Pavement Rutting Characteristics by Additives. M.Sc., Thesis. El-Mansoura University. 2000.

[18] Naglaa, K. R., "The Use Of Additives In Improved Pavement Mix Design" , A thesis Submitted to the University of Al-Minia for the Degree Doctor of Philosophy, 2009.

[19] BISAR-PC User's Manual: Shell International Petroleum Company, London, UK, 1995.

\section{Symbols and abbreviations}

HMA
UPR
ER
UPRER
Epoxy Resin
AV
VMA
VFA
E
$v$
$\mathrm{M}_{\mathrm{r}}$

Hot Mix Asphalt

Unsaturated Polyester Resin

Epoxy Resin

Unsaturated Polyester Resin mixed with 3\%

Air Voids

Voids in Mineral Aggregate

Voids Filled with Bitumen

Modulus of Elasticity

Poisson's ratio

Modulus of Resilience

Journal of Engineering Sciences, Assiut University, Faculty of Engineering, Vol. 41, No. 3, May, 2013, E-mail address: jes@aun.edu.eg 
M. D. Hashem, N. K. Rashwan, The influence of resin modifiers on the performance of hot mix asphalt, pp. 867 - 885

$\mathrm{a}_{1}$

$\mathrm{a}_{2}$

$\mathrm{a}_{3}$

$\mathrm{SN}_{1}$

$\mathrm{SN}_{2}$

$\mathrm{SN}_{3}$
Surface Layer Coefficient

Base Course Layer Coefficient

Subbase Layer Coefficient

Structure Number for Surface Layer

Structure Number for Base Course Layer

Structure Number for Subbase Layer

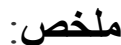

من أجل در اسة تأثثير اضافة المواد الراتنجينية على أداء الخلطات الإسفلتية الساخنة تم اختيار نوعين

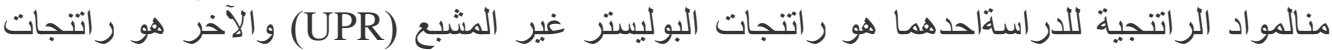

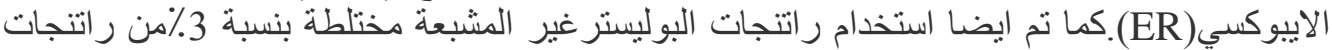

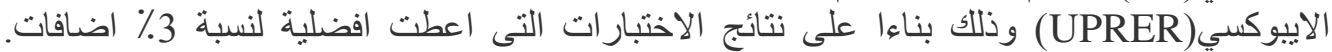

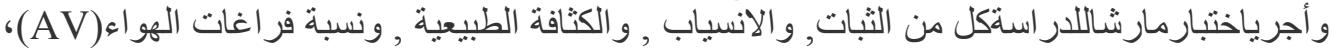

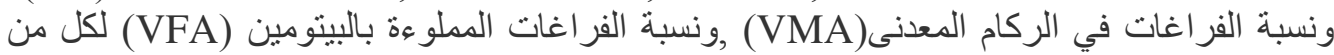

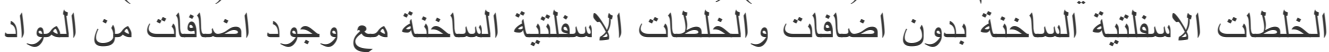
الر اتتجية بنسب اضافات مختلفة. كما تم استخدام برنامج كمبيوتر يسمىBISARلتحديد كل من الاجهاد و الانفعال الكلى و الحركة الافقية

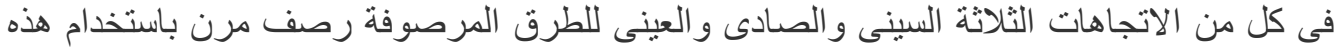

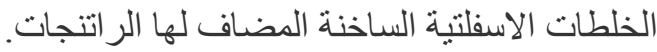

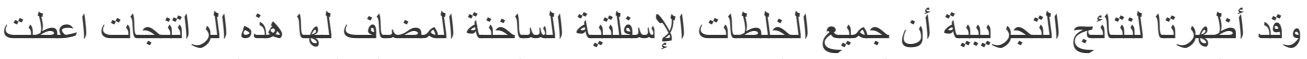

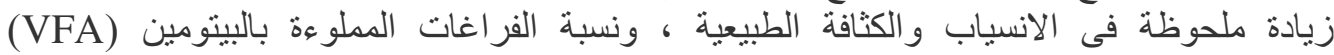

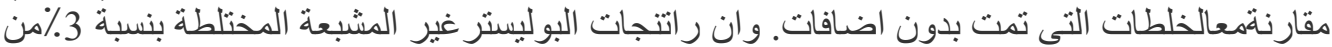

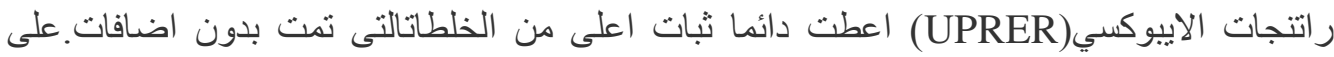

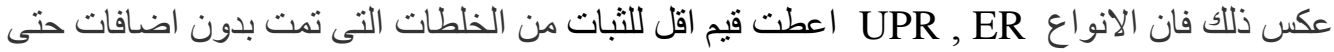

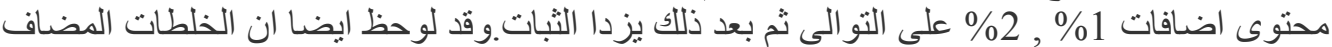

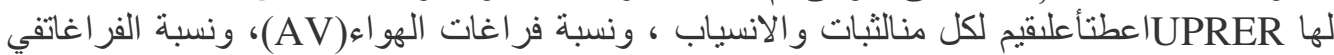

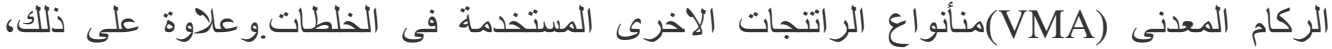

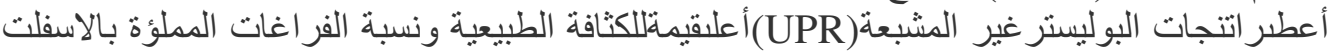

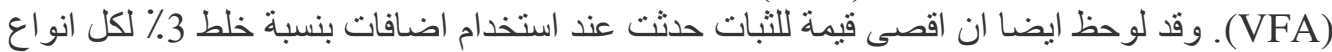
الر اتنجات.

وتم استتاج ان الاجهاد والانفعال الكلى يزداد نسبيا مع زيادة عمق الرصف حتى عمق 10 سم ثم بعد

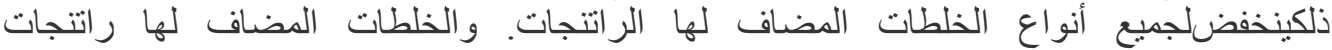

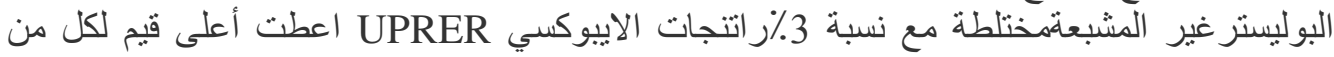

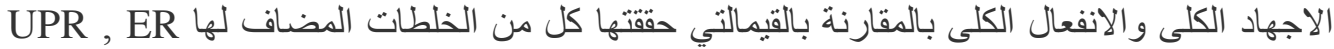

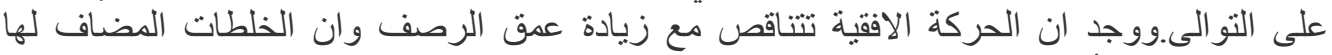

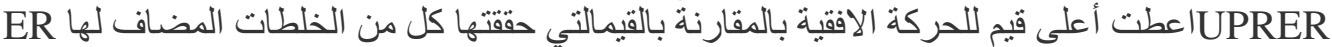

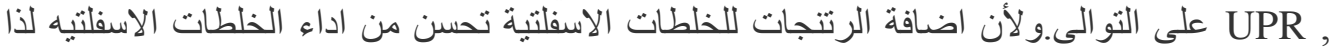
فانها ستكون ذات فائدة كبيرة للمجال هندسة الطرق الطنات

Journal of Engineering Sciences, Assiut University, Faculty of Engineering, Vol. 41, No. 3, May, 2013, E-mail address: jes@aun.edu.eg 